\title{
Comparison of Multilevel Growth Models for Respiratory Function in Patients with Tracheostomy and Stroke using Cervical Range of Motion Training
}

\author{
Kim SoHyun ${ }^{a}$, Cho SungHyoun ${ }^{b}$ \\ aDepartment of Medical Sciences, The Graduate School, Nambu University, Gwangju, Republic of Korea \\ ${ }^{b}$ Department of Physical Therapy, Nambu University, Gwangju, Republic of Korea
}

\begin{abstract}
Objective: The purpose of this study was to investigate the effect of cervical range of motion training on the change in respiratory function growth rate at the group and individual level in stroke patients and stroke patients with tracheostomy tube.
\end{abstract}

Design: A Multilevel Growth Model

Methods: 8 general stroke patients and 6 stroke patients who had a tracheostomy tube inserted were subjected to cervical range of motion training 3 times a week for 4 weeks. Force vital capacity (FVC), Forced expiratory volume in the first second (FEV1), Forced expiration ratio (FEV1/FVC) and Manual assist peak cough flow (MPCF) were measured. Data were analyzed using descriptive statistics and multilevel analysis with HLM 8.0.

Results: A significant difference was found in the respiratory function analysis growth rate of the entire group ( $p<0.05)$, and two groups were added to the research model. The linear growth rate of respiratory function in patients with general stroke increased with the exception of FEV1/FVC $(p<0.05)$. Stroke patients with tracheostomy tube showed a decreasing pattern except for FVC. In particular, MPCF showed a significantly decreased result $(\mathrm{p}<0.05)$.

Conclusions: This study found that the maintenance of improved respiratory function in stroke patients with tracheostomy tube decreased over time. However, cervical range of motion training is still a useful method for respiratory function in general stroke patients and stroke patients with tracheostomy tube.

Key Words: Cervical range of motion, Multilevel Growth Model, Respiratory function, Stroke, Tracheostomy

서론

뇌졸중은 전 세계적인 사망원인 중 하나로 만성적인 장 애를 남기는 것으로 알려져 있다[1]. 특히, 뇌졸중 환자의 호흡 기능(Respiratory function) 장애는 생명유지와 밀접 한 관계에 놓여 있다. 뇌졸중 환자의 비정상적 자세와 마 비 측의 가로막과 같은 주 호흡 근육의 무사용(Disuse), 비정상적 흥곽확장으로 인한 비대칭적 호흡 패턴은 폐 용 적의 감소로 호흡기까지 침범하여 재활의 충분한 고려가 필요하다 $[2,3]$.

뇌졸중 환자의 기침 능력의 감소는 기도 내의 분비물 제거를 어렵게 하기 때문에 호흡기계 위생에 심각한 문제 를 야기시켜 폐렴 등의 합병증을 발생시킨다[4]. 이러한
문제를 해결하기 위해 호흡능력이 저하된 뇌졸중 환자의 기관절개술(Tracheostomy) 삽관은 낮은 기도저항과 청결, 안정성 증가 등 여러 이점을 가져온다[5]. 그러나 삽관의 장기화는 폐렴 유병률을 높이며[6], 폐쇄, 폐확장부전, 흥 터, 거짓 통로 발생, 성대 아래 기관 협착 등이 발생한다 [7]. 폐렴은 뇌졸중 환자의 높은 사망률 및 입원 비용과 관련이 있으며, 폐렴을 예방하는 것은 모든 위험 수준에 서 최우선이 되어야 한다[8]. 따라서 뇌졸중 환자에게 적 절한 호흡훈련을 적용하여 호흡과 기침능력을 회복하는 것은 매우 중요하다.

선행연구에서는 기관절개관을 삽입한 환자가 목뼈 움 직임에 제한을 나타낸다고 보고하고 있으며[9], 목뼈 움직 임의 제한된 범위는 비정상적 자세와 근육의 불균형을 유 
발하고 호흡기능에 영향을 미치게 된다고 하였다[10]. 이 에 따라 최근 뇌졸중 환자의 호흡기능을 향상시키기 위해 목 안정화 훈련[11]과 목뼈 가동 범위 훈련[12] 연구가 다 양하게 이루어지고 있다. 그러나 기존의 연구는 각 시점 에 따른 평균값 차이와 효과성만을 나타내어 집단과 개인 의 기초 값에 대한 선형 성장률 파악이 어렵다[13]. 이를 보완하기 위해 활용되는 다층 성장 모형의 도입은 개인의 변화를 관찰하는데 적절한 모형으로 반복 측정치를 각 수 준에서 분산 구분이 가능하며[14], 다시 말해 집단 전체 평균 비교가 아닌 개인별 처치 효과에 대한 명확한 파악 이 가능하다.

따라서 본 연구는 일반 뇌졸중 환자와 기관절개술을 시 행한 뇌졸중 환자를 대상으로 목뼈 가동 범위 훈련이 집 단과 개인 수준의 호흡기능 성장률의 변화량에 미치는 영 향을 알아보고, 각 개인별 종단적 관찰로 훈련의 효과성 에 대하여 입증하고자 하였다.

\section{연구 방법}

\section{연구 대상}

본 연구의 대상자는 광주광역시에 위치한 $\mathrm{S}$ 재활병원에 입원중인 일반 뇌졸중 환자 8 명, 기관절개관을 삽입한 뇌졸 중 환자 6 명으로 총 14 명이 참여하였다. 헬싱키 선언에 입 각하여 충분한 설명을 제공하였으며, 각 대상자들은 자발적 인 참여 의사를 밝힌 동의서를 작성하였다. 대상자들은 호 흡기질환과 손상 병력이 없으며, 흥부 이학적 소견에서 폐 질환 소견이 없는 자, 심각한 수준의 실어증이나 인지기능 장애가 없는 자(MMSE-K 24점 이상)로 선정하였다.

\section{중재 방법}

목뼈 가동 범위 운동은 4주 동안 주 3 회 시행되었으며, 훈련 방법은 선행연구를 참고하였다[15]. 훈련은 임상경 력 5년 이상의 물리치료사 2명이 시행하였으며, 훈련 전 누운 자세에서 목의 굽힘(Flexion), 폄(Extension), 가쪽굽 힘(Lateral flexion), 돌림(Rotation)을 통해 위 등 세모근 과 목빗근, 어깨 올림근 등 스트레칭을 각 30 초간 수동적 으로 두 번 실시하였다. 목뼈의 가동범위는 기관절개관 삽입 환자가 불편함을 느끼는 것을 방지하기 위하여, 굽 힘과 폄을 10 도, 가쪽굽힘은 10 도, 돌림은 20 도를 최대 한계로 설정하였다.

\section{측정방법 및 도구}

\section{호흡기능 평가}

본 연구에서는 폐활량계(MicroLab 3300 Spirometer
MK4, Micro Medical Ltd, UK)를 사용하여 노력성 폐활 량(Forced vital capacity, FVC), 1초간 노력성호기량 (Forced expiratory volume at one second, FEV1), 노력 성 폐활량비(Forced expiratory ratio, FEV1/FVC)를 평 가하였다[16]. 참가자들은 병실 침대의 전동 각도 조절장 치를 사용하여 $60^{\circ}$ 로 상체를 세운 후, 일반 뇌졸중 환자 는 코 마개를 사용하였고, 기관절개관을 삽입한 환자는 기관절개 마개와 코 마개를 이용하여 공기 누출을 방지하 였다. 참가자들은 안정된 상태에서 세 번 호흡을 수행하 였고, 물리치료사의 구두 아래, $\mathrm{FVC}$ 는 최대한 공기를 들 어 마신 다음 가능한 빨리 내쉰 공기의 양을 측정하였다. 또한 $\mathrm{FEV} 1$ 은 최대한 공기를 들어 마시고 1 초간 강하게 내쉰 공기의 양을 측정하였다. 각각 세번의 검사를 통해 평균 값을 기록하였다.

\section{기츰능력 평가}

일반 뇌졸중 환자와 기관절개관 삽입 뇌졸중 환자의 기 침 능력 저하를 고려하여 도수 보조 최대 기침 유량 (Manual assist peak cough flow, MPCF)으로 진행하였 다. 측정은 최대기침 유량 측정기(Mini-wright AFS Low range peak flow meter, Cardinal Health 232 Ltd, UK) 를 사용하였다[17]. 환자의 자세는 호흡기능 측정방법과 동일하게 진행하였으며, 환자 스스로 최대한 공기를 들어 마시게 한 후 기침을 유도하여 물리치료사가 수동적으로 복부를 밀어주어 측정하였다. 각각 세번의 검사를 통해 평균값을 기록하였다.

\section{자료 분석}

수집된 방법은 $\operatorname{HLM}(8.0$ Version, Scientific Software International Inc., USA) 프로그램을 이용하여 전산통계 처리하였으며, 구체적인 분석방법은 다음과 같다. 연구대 상의 일반적 특성과 연구변수의 서술적 통계는 빈도, 백 분율, 평균, 표준편차 등을 이용하였다. 실험효과분석으로 는 기관절개술을 시행한 뇌졸중 환자와 일반 뇌졸중 환자 수준의 연구변수가 호흡 기능 지표에 어떠한 영향을 미치 는지 확인하기 위해 다층성장모형을 실시하였다.

\section{연구 결과}

\section{연구대상의 일반적 특성}

선정된 실험집단의 분포를 살펴보면 Table 1과 같다. 연구에 참여한 전체 대상자는 총 14 명으로 기관절개술을 시행한 뇌졸중 환자 6명, 일반 뇌졸중 환자 8 명이었다. 남 성이 2명(14.29\%), 여성이 12 명(85.71\%) 으로 여성의 비 
Table 1. General Characteristics of Participants

\begin{tabular}{llll}
\hline & Total $(\mathbf{n}=\mathbf{1 4})$ & Tracheostomy $(\mathbf{n}=\mathbf{6})$ & Stroke $(\mathbf{n}=\mathbf{8})$ \\
\hline Gender $(\mathrm{M} / \mathrm{F})$ & $2 / 12$ & $1 / 5$ & $1 / 7$ \\
Age $($ years $)$ & $76.00 \pm 10.19$ & $80.50 \pm 5.61$ & $73.88 \pm 12.79$ \\
Height $(\mathrm{cm})$ & $159.86 \pm 6.93$ & $154.75 \pm 3.67$ & $158.14 \pm 5.01$ \\
Weight $(\mathrm{kg})$ & $53.56 \pm 9.27$ & $42.87 \pm 8.67$ & $57.28 \pm 8.06$ \\
BMI $\left(\mathrm{kg} / \mathrm{cm}^{2}\right)$ & $20.96 \pm 3.45$ & $17.92 \pm 3.64$ & $22.95 \pm 3.38$ \\
Onset (month) & $31.50 \pm 16.72$ & $31.67 \pm 20.73$ & $31.38 \pm 14.57$ \\
\hline
\end{tabular}

Mean \pm standard deviation $($ Mean \pm SD)

Table 2. Descriptive statistics results and variable values

\begin{tabular}{lllll}
\hline Variable name & Mean & SD & Minimum & Maximum \\
\hline FVC $(\mathrm{ml})$ & 1325.36 & 546.57 & 400.00 & 2980.00 \\
FEV1 $(\mathrm{ml})$ & 1128.63 & 527.85 & 260.00 & 2450.00 \\
FEV1/FVC (\%) & 83.10 & 13.37 & 42.00 & 99.00 \\
MPCF $(\mathrm{L} / \mathrm{min})$ & 136.79 & 74.30 & 50.00 & 300.00 \\
\hline
\end{tabular}

Standard deviation (SD)

FVC: Forced vital capacity, FEV1: Forced expiratory volume at one second, FEV1/FVC: Forced expiratory ratio, MPCF: Manual assist peak cough flow

율이 높았다.

분석에서 사용된 변인들의 기술통계 결과와 변수 값은

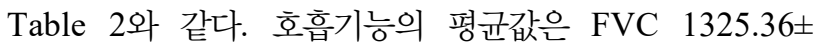
$546.57 \mathrm{ml}$, FEV1 1128.63 $\pm 527.85 \mathrm{ml}, \mathrm{FEV1} / \mathrm{FVC} 83.10 \pm$ $13.37 \%, \mathrm{MPCF}$ 는 $136.79 \pm 74.30 \mathrm{~L} / \mathrm{min}$ 이었다.

\section{다층성장모형의 분석 결과}

\section{기본모형(null model)}

기본모형은 독립변수를 한 개도 투입하지 않은 모형을 의미한다. 즉, 추후 시행할 연구모형에서 기본모형의 Level-2에 독립변수를 투입할 것인가에 대한 판단을 내리 는 과정이다[18].

$\mathrm{mj}$ 는 집단 $\mathrm{j}$ 에서의 개인 $\mathrm{m}$ 의 측정치로 모형의 종속변 수에 해당한다. TIMEmj는 집단 $\mathrm{j}$ 에서의 개인 $\mathrm{m}$ 의 특성 변수로 종속변수를 예측 또는 설명하기 위한 독립변수이 다. $\psi 0 \mathrm{j}$ 는 1 수준의 계수(level- 1 coefficients)로 평균의 영 향력에 대한 회귀계수이다. $\psi 1 \mathrm{j}$ 는 1 수준의 계수(level-1 coefficients)로 Xij의 영향력에 대한 계수이다. emj는 1수 준의 무선효과(level-1 random effect)로 집단 j에서의 개 인m의 측정치에 대하여, 독립변수에 의해 설명되지 않는 부분인 잔차(residual), 즉 무선오차를 의미한다. 2수준 모
형은 1 수준의 계수인 $\psi 0 \mathrm{j}, \psi 1 \mathrm{j}$ 를 예측 또는 설명하기 위 한 모형이다. 각 호흡기능의 변수를 투입한 모형구성은 다음과 같다.

$$
\begin{aligned}
& \text { Level-1 모형 } \\
& \text { (호흡기능)mj }=\psi 0 j+\psi 1 j *(\text { TIMEmj })+\text { emj }
\end{aligned}
$$

Level-2 모형

$$
\begin{aligned}
\psi 0 \mathrm{j} & =\gamma 00+\mathrm{u} 0 \mathrm{j} \\
\psi 1 \mathrm{j} & =\gamma 10+\mathrm{u} 1 \mathrm{j}
\end{aligned}
$$

전체집단의 호흡기능 선형 성장률의 변화는 다음과 같다 (Table 3, Figure 1). 측정 기간 동안 전체 대상자의 $\mathrm{FVC}$ 점수의 선형성장률은 37.94로 통계적으로 유의미하였다. 전체집단의 $\mathrm{FVC}$ 는 평균 $37.94 \mathrm{ml}$ 향상되었다. 측정 기간 동안 전체 대상자의 $\mathrm{FEV} 1$ 점수의 선형성장률은 33.90 로 통계적으로 유의미하였다. 전체집단의 $\mathrm{FEV1}$ 는 평균 $33.90 \mathrm{ml}$ 향상되었다. 측정 기간 동안 전체 대상자의 $\mathrm{FEV} 1 / \mathrm{FVC}$ 점수의 선형성장률은 0.12 로 통계적으로 유의 한 차이가 없었다 $(\mathrm{p}>0.05)$. 측정 기간 동안 전체 대상자의 $\mathrm{MPCF}$ 점수의 선형성장률은 7.12로 통계적으로 유의미하 였다. 전체집단의 $\mathrm{MPCF}$ 는 평균 $7.12 \mathrm{~L} / \mathrm{min}$ 향상되었다. 
Table 3. Changes in respiratory function of the entire groups

\begin{tabular}{|c|c|c|c|c|}
\hline Variable & Fixed effect & Coefficient & Standard error & t-ratio \\
\hline \multirow{6}{*}{$\mathrm{FVC}$} & Initial value average & 1116.70 & 132.11 & $8.453^{* *}$ \\
\hline & Linear growth rate average & 37.94 & 8.34 & $4.549^{* *}$ \\
\hline & Random effect & Variance Component & Standard Deviation & \\
\hline & Within the group & 260663.48 & 510.55 & $1374.880^{* *}$ \\
\hline & Intergroup & 989.44 & 31.46 & $230.980^{* *}$ \\
\hline & Error variance & 8438.23 & 91.86 & \\
\hline Variable & Fixed effect & Coefficient & Standard error & t-ratio \\
\hline \multirow{6}{*}{ FEV1 } & Initial value average & 942.16 & 125.29 & $7.520^{* *}$ \\
\hline & Linear growth rate average & 33.90 & 8.53 & $3.977^{* *}$ \\
\hline & Random effect & Variance Component & Standard Deviation & \\
\hline & Within the group & 234672.53 & 484.43 & $1553.432^{* *}$ \\
\hline & Intergroup & 1048.98 & 32.39 & $303.347^{* *}$ \\
\hline & Error variance & 6716.30 & 81.96 & \\
\hline Variable & Fixed effect & Coefficient & Standard error & t-ratio \\
\hline \multirow{6}{*}{ FEV1/FVC } & Initial value average & 82.43 & 3.30 & $25.006^{* *}$ \\
\hline & Linear growth rate average & 0.12 & 0.24 & 0.510 \\
\hline & Random effect & Variance Component & Standard Deviation & \\
\hline & Within the group & 154.91 & 12.45 & $238.679^{* *}$ \\
\hline & Intergroup & 0.65 & 0.81 & $53.183^{* *}$ \\
\hline & Error variance & 30.26 & 5.50 & \\
\hline Variable & Fixed effect & Coefficient & Standard error & t-ratio \\
\hline \multirow{6}{*}{ MPCF } & Initial value average & 97.64 & 13.35 & $7.317^{* *}$ \\
\hline & Linear growth rate average & 7.12 & 1.36 & $5.222^{* *}$ \\
\hline & Random effect & Variance Component & Standard Deviation & \\
\hline & Within the group & 2644.66 & 51.43 & $867.730^{* *}$ \\
\hline & Intergroup & 27.06 & 5.20 & $381.762^{* *}$ \\
\hline & Error variance & 136.41 & 11.68 & \\
\hline
\end{tabular}

${ }^{*} \mathrm{p}<0.05,{ }^{* *} \mathrm{p}<0.01$

Initial value average: For INTRCPT1, $\psi 0$ INTRCPT2, $\gamma 00$, Linear growth rate average: For TIME slope, $\psi 1$ INTRCPT2, $\gamma$ 10, Within the group: INTRCPT1, u0, Intergroup: TIME slope, u1, Error variance: level-1, e

\section{연구모형(Research model)}

연구모형에서는 기관절개술 집단과 일반 뇌졸중 집단 의 호흡기능에 대한 효과를 살펴보기 위하여 다음의 성장 모형식을 적용하여 분석하였다. GROUPj는 2수준 독립 변수이며, 집단 $\mathrm{j}$ 의 특성변수다. $\gamma 00, \gamma 10, \gamma 01, \gamma 11$ 은 2 수준의 계수(Level-2 cofficients)로 고정효과(Fixed effects) 모수이다. $\gamma 00, \gamma 10$ 은 2수준 모형의 절편을, $\gamma 01$ 는 2수준 독립변수(GROUPj)의 효과를, $\gamma 11$ 는 1수준 독
립변수와 2수준 독립변수의 상호작용 효과를 의미한다. $\mathrm{emj}, \mathrm{u} 0 \mathrm{j}, \mathrm{u} 1 \mathrm{j}$ 는 무선효과(Random effect)모수를 의미한 다. $\mathrm{u} 0 \mathrm{j}$ 와 $\mathrm{u} 1 \mathrm{j}$ 는 2수준의 무선효과(Level-2 random effect)로 집단수준의 독립변수가 설명하지 못한 각 집단 별 잔차다.

Level-1 모형

$$
(\text { 호흡기능 }) m j=\psi 0 j+\psi 1 j *(\text { TIMEmj })+e m j
$$


(A)

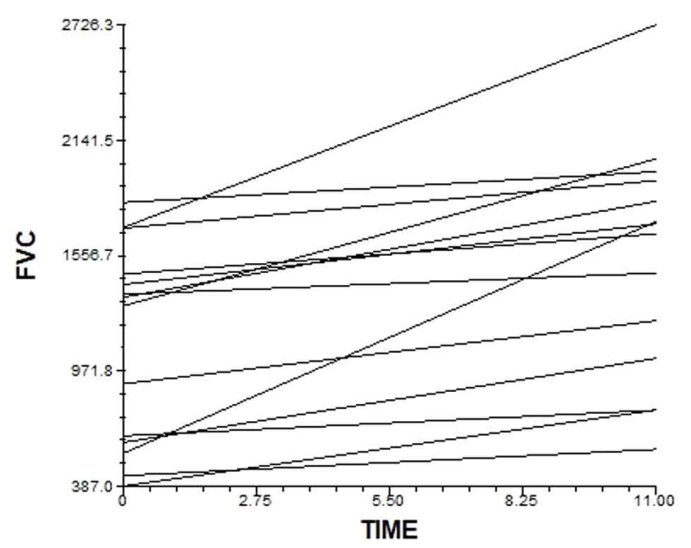

(C)

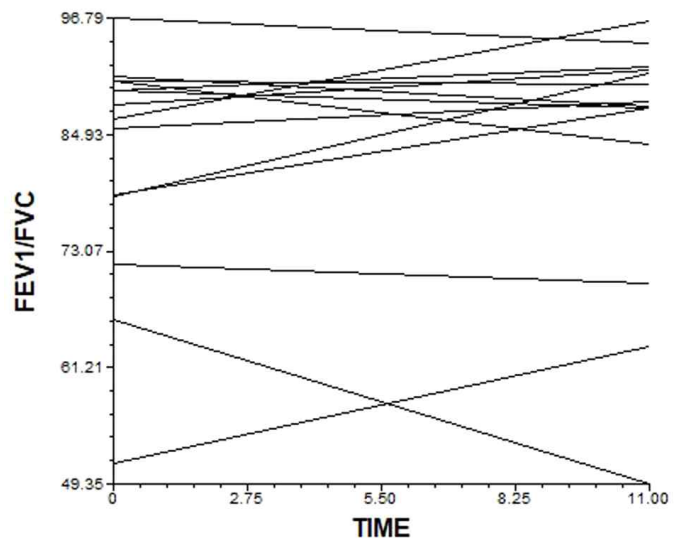

(B)

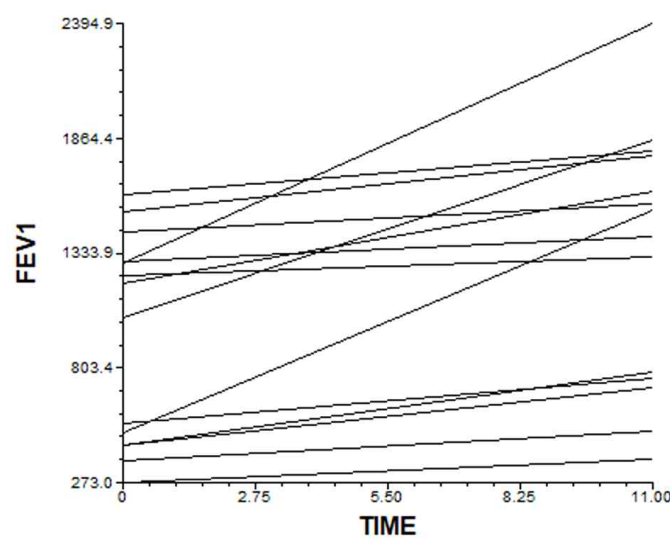

(D)

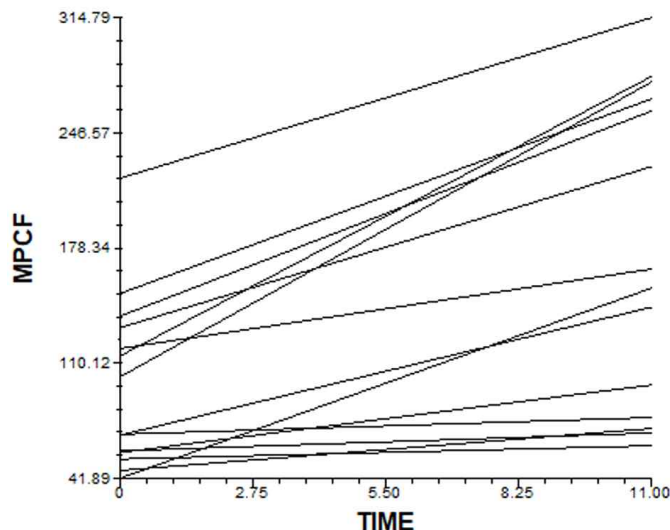

Figure 1. Initial value and change amount of the entire group. (A) Force vital capacity, (B) Forced expiratory volume in the first second, (C) Forced expiratory volume in the first second/Force vital capacity, (D) Manual assist peak cough flow

Level-2 모형

$$
\begin{aligned}
& \psi 0 \mathrm{j}=\gamma 00+\gamma 01 *(\text { GROUPj })+\mathrm{u} 0 \mathrm{j} \\
& \psi 1 \mathrm{j}=\gamma 10+\gamma 11 *(\text { GROUPj })+\mathrm{u} 1 \mathrm{j}
\end{aligned}
$$

두 집단의 호흡기능의 변화를 살펴보면 다음과 같다 (Table 4, Figure 2). 기관절개술 집단과 일반 뇌졸중 집단 간의 $\mathrm{FVC}$ 의 초기값은 유의미한 차이가 있었고, 일반 뇌졸 중 집단의 평균 선형성장률은 유의미한 차이가 나타났다. 일반 뇌졸중 집단의 성장률은 37.20 으로 양 $(+)$ 적으로 증가 하고 $(\mathrm{p}<0.01)$, 기관절개술 집단의 성장률은 1.71 으로 양 $(+)$ 의 성장이 나타났으나 유의미한 차이가 없었다 $(\mathrm{p}>$ $0.05)$. 즉, 일반 뇌졸중 집단은 초기 $\mathrm{FVC}$ 에서 차이가 나 타났으며, 목뼈 가동 범위 훈련에 참여하면서 $\mathrm{FVC}$ 가 시간 이 지날수록 평균 $37.20 \mathrm{ml}$ 만큼 향상된 것을 알 수 있다.

기관절개술 집단과 일반 뇌졸중 집단 간의 FEV1의 초 기값은 유의미한 차이가 있었고, 일반 뇌졸중 집단의 평 균 선형성장률은 유의미한 차이가 나타났다. 일반 뇌졸중 집단의 성장률은 33.90 으로 양 $(+)$ 적으로 증가하고 $(\mathrm{p}$
$<0.01)$, 기관절개술 집단의 성장률은 -4.04 으로 부 $(-)$ 적 으로 감소하였으나 유의미한 차이가 없었다 $(\mathrm{p}>0.05)$. 즉, 일반 뇌졸중 집단은 초기 FEV1에서 차이가 나타났으며, 목뼈 가동 범위 훈련에 참여하면서 FEV1이 시간이 지날 수록 평균 $33.90 \mathrm{ml}$ 만큼 향상된 것을 알 수 있다.

기관절개술 집단과 일반 뇌졸중 집단 간의 $\mathrm{FEV} 1 / \mathrm{FVC}$ 의 초기값은 유의미한 차이가 있었고, 일반 뇌졸중 집단과 기관절개술 집단의 평균 선형성장률은 유의미한 차이가 없 었다. 일반 뇌졸중 집단의 성장률은 0.18 으로 양 $(+)$ 적으 로 증가하고, 기관절개술 집단의 성장률은 -0.14 로 부 $(-)$ 적으로 감소하였으나, 유의미한 차이가 없었다 $(\mathrm{p}>0.05)$.

기관절개술 집단과 일반 뇌졸중 집단 간의 $\mathrm{MPCF}$ 의 초기값은 유의미한 차이가 있었고, 기관절개술 집단과 일 반 뇌졸중 집단의 평균 선형성장률은 유의미한 차이가 나 타났다. 기관절개술 집단의 성장률은 -7.97 로 부(-)적으 로 감소하고, 일반 뇌졸중 집단의 성장률은 10.54 으로 양 $(+)$ 의 성장이 나타났다 $(\mathrm{p}<0.01)$. 일반 뇌졸중 집단과 기 관절개술 집단은 초기 $\mathrm{MPCF}$ 에서 차이가 나타났으며, 
Table 4. Changes in respiratory function in stroke patients and stroke patients with tracheostomy tube inserted

\begin{tabular}{|c|c|c|c|c|c|}
\hline Variable & Fixed effect & Group & Coefficient & Standard error & t-ratio \\
\hline \multirow{8}{*}{$\mathrm{FVC}$} & \multirow{2}{*}{ Initial value average } & Stroke & 1512.26 & 69.65 & $21.714^{* *}$ \\
\hline & & T. stroke & -922.97 & 100.62 & $-9.173^{* *}$ \\
\hline & \multirow{2}{*}{ Linear growth rate average } & Stroke & 37.20 & 10.28 & $3.620^{* *}$ \\
\hline & & T. stroke & 1.71 & 17.21 & 0.100 \\
\hline & Random effect & \multicolumn{2}{|c|}{ Variance Component } & \multicolumn{2}{|c|}{ Standard Deviation } \\
\hline & Within the group & 39203.10 & & 198.0 & $201.068^{* *}$ \\
\hline & Intergroup & 1075.97 & & 32.80 & $230.809^{* *}$ \\
\hline & Error variance & 8438.23 & & 91.86 & \\
\hline Variable & Fixed effect & Group & Coefficient & Standard error & t-ratio \\
\hline \multirow{8}{*}{ FEV1 } & \multirow{2}{*}{ Initial value average } & Stroke & 942.16 & 41.18 & $22.880^{* *}$ \\
\hline & & T. stroke & -894.64 & 76.34 & $-11.720^{* *}$ \\
\hline & \multirow{2}{*}{ Linear growth rate average } & Stroke & 33.90 & 8.51 & $3.984 * *$ \\
\hline & & T. stroke & -4.04 & 16.87 & -0.239 \\
\hline & Random effect & Variance C & lent & Standard Devia & \\
\hline & Within the group & 25715.06 & & 160.36 & $167.814^{* *}$ \\
\hline & Intergroup & 1135.66 & & 33.70 & $302.158^{* *}$ \\
\hline & Error variance & 6716.30 & & 81.95 & \\
\hline Variable & Fixed effect & Group & Coefficient & Standard error & t-ratio \\
\hline \multirow{8}{*}{$\begin{array}{l}\text { FEV1/ } \\
\text { FVC }\end{array}$} & \multirow{2}{*}{ Initial value average } & Stroke & 87.72 & 2.35 & $37.271 * *$ \\
\hline & & T. stroke & -12.36 & 6.35 & -1.946 \\
\hline & \multirow{2}{*}{ Linear growth rate average } & Stroke & 0.18 & 0.25 & 0.744 \\
\hline & & T. stroke & -0.14 & 0.51 & -0.275 \\
\hline & Random effect & Variance C & ent & Standard Devia & \\
\hline & Within the group & 124.95 & & 11.18 & $180.031^{* *}$ \\
\hline & Intergroup & 0.72 & & 0.85 & $52.859^{* *}$ \\
\hline & Error variance & 30.26 & & 5.50 & \\
\hline Variable & Fixed effect & Group & Coefficient & Standard error & t-ratio \\
\hline \multirow{8}{*}{ MPCF } & \multirow{2}{*}{ Initial value average } & Stroke & 127.11 & 16.94 & $7.504^{* *}$ \\
\hline & & T. stroke & -68.76 & 17.21 & $-3.996^{* *}$ \\
\hline & \multirow{2}{*}{ Linear growth rate average } & Stroke & 10.54 & 1.33 & $7.935^{* *}$ \\
\hline & & T. stroke & -7.97 & 1.64 & $-4.863^{* *}$ \\
\hline & Random effect & Variance C & ient & Standard Devia & \\
\hline & Within the group & 1517.43 & & 38.95 & $464.695^{* *}$ \\
\hline & Intergroup & 11.23 & & 3.35 & $153.216^{* *}$ \\
\hline & Error variance & 136.41 & & 11.68 & \\
\hline
\end{tabular}

${ }^{*} \mathrm{p}<0.05,{ }^{* *} \mathrm{p}<0.01$

Initial value average: For INTRCPT1, $\psi 0$, Stroke: INTRCPT1, u0, T. Stroke (TracheostomyStroke): Group, $\gamma 01$, Linear growth rate average: For TIME slope, $\psi 1$, Stroke: INTRCPT2, $\gamma 10$, T. Stroke (Tracheostomystroke): Group, $\gamma 11$, Within the group: INTRCPT1, u0, Intergroup: TIME slope, u1, Error variance: level-1, e 
(A)

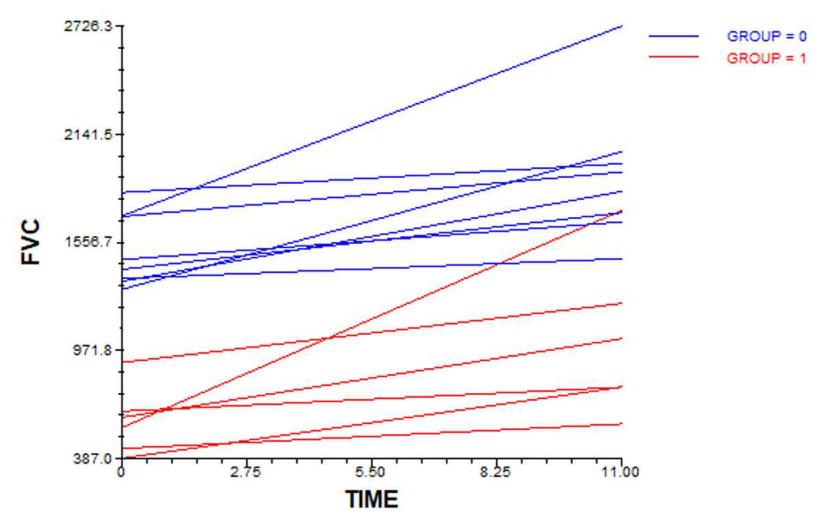

(C)

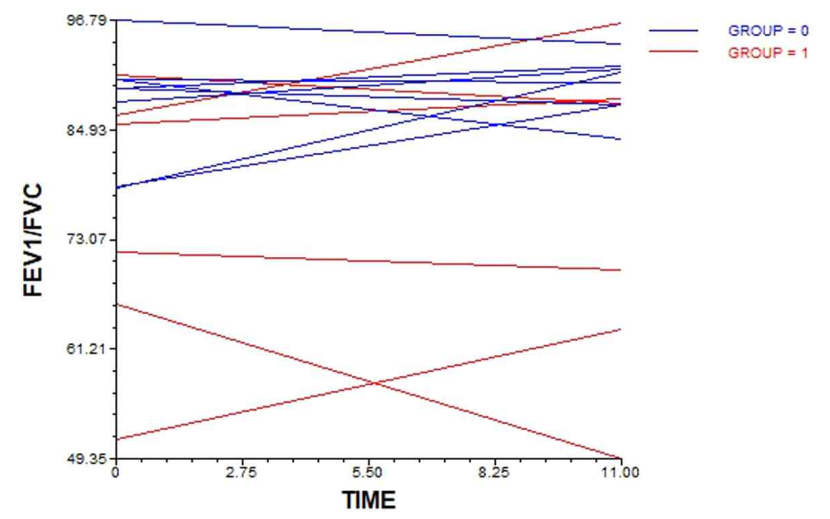

(B)

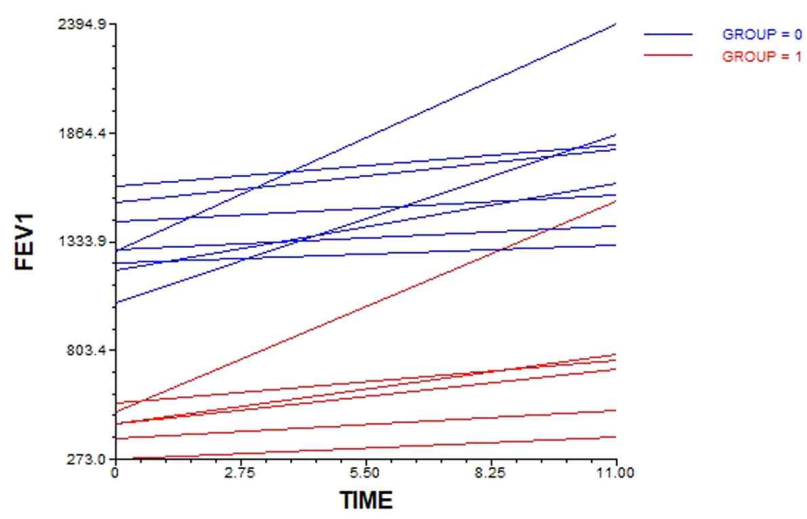

(D)

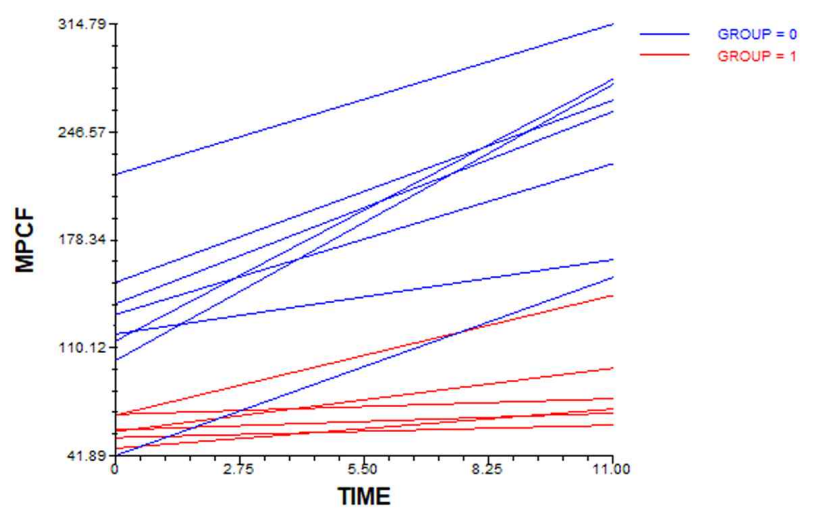

Figure 2. Initial value and amount of change according to respiratory function in stroke patients and stroke patients with tracheostomy tube inserted. (A) Force vital capacity, (B) Forced expiratory volume in the first second, (C) Forced expiratory volume in the first second/Force vital capacity, (D) Manual assist peak cough flow, GROUP=0: Stroke, GROUP=1: Tracheostomy stroke

목뼈 가동 범위 훈련에 참여하면서 일반 뇌졸중 집단은 $\mathrm{MPCF}$ 가 시간이 지날수록 평균 $10.54 \mathrm{~L} / \mathrm{min}$ 만큼 향상 되었다. 그리고 기관절개술 집단은 $\mathrm{MPCF}$ 가 시간이 지날 수록 평균 $-7.97 \mathrm{~L} / \mathrm{min}$ 만큼 감소하였다.

\section{고찰}

본 연구는 일반 뇌졸중 환자와 기관절개관을 삽입한 뇌 졸중 환자의 호흡기능과 기침능력의 지표인 $\mathrm{FVC}, \mathrm{FEV} 1$, $\mathrm{FEV} 1 / \mathrm{FVC}, \mathrm{MPCF}$ 를 향상시키기 위해 목뼈 가동범위 훈 련을 시행하여 집단 비교가 아닌 집단과 개인 별 성장 궤 적으로 효과성을 입증하고자 하였다.

호흡기능과 기침능력은 기도 내 청결함을 유지하고 분 비물을 외부로 배출시키는 중요한 보호기능으로써, 뇌졸 중 환자들은 전반적인 호흡근육의 약화로 기침이라는 보호 기전이 저하하게 된다[19]. $\mathrm{FVC}$ 의 정상 수치는 남성 3600 $\mathrm{ml}$, 여성 $2500 \mathrm{ml}, \mathrm{FEV} 1$ 의 경우 남성 $2500 \mathrm{ml}$, 여성
$1800 \mathrm{ml}$ 정도이며[20], 본연구의 대상자 $\mathrm{FVC}$ 값은 1325 $\mathrm{ml}, \mathrm{FEV} 1$ 값은 $1128 \mathrm{ml}$ 로 다소 낮은 것을 볼 수 있다. 또한, 기침 유량의 정상 수치는 $360 ~ 400 \mathrm{~L} / \mathrm{min}[21]$, 가 래를 내보내기 위해서는 적어도 $160 \sim 200 \mathrm{~L} / \mathrm{min}[22]$ 을 초과해야 한다. 본 연구에 참여한 뇌졸중 환자의 기침유 량이 $137 \mathrm{~L} / \mathrm{min}$ 를 감안한다면, 매우 낮은 수치이다. 이는 뇌졸중 환자의 분비물 제거 능력이 현저히 떨어지고 기침 능력이 손실되어 폐렴 등 다양한 합병증에 노출될 수 있 다는 것을 의미한다. 기관 절개 환자의 성공적인 발관은 만성 중증 환자의 회복에 중요한 단계이며, 기침 능력이 온전하게 회복되어야 한다[23]. 그러므로 기관절개관의 제거를 위해 호흡과 기침능력의 향상을 위한 훈련은 필수 적이라 할 수 있다. 따라서 본 연구의 결과는 목뼈 가동 범위 훈련을 적용하여 뇌졸중 환자의 호흡 기능과 기침 유량의 향상을 보인 선행 연구와 일치하는 결과를 보였으 며[24], 이로써 목뼈 가동 범위 훈련이 기관절개관을 제거 하는데 도움을 줄 수 있는 훈련임을 나타냈다. 
또한, 만성 뇌졸중 환자에게 목뼈 관절 가동 기술을 수 행한 연구에서도 본 연구와 마찬가지로 FVC, FEV1이 유 의한 차이를 보였으며, $\mathrm{FEV1/FVC는} \mathrm{유의하지} \mathrm{않은} \mathrm{것을}$ 확인할 수 있었다[25]. 그러나 이전 연구는 집단 자체의 각 시점 평균값을 비교하여 효과성만을 파악하였고, 각 집단과 개인의 선형 성장률은 파악하지 못하였다. 즉, 중 재를 반복할수록 효과를 유지하는 것에 대한 증감의 여부 는 확인할 수 없는 것이다. 따라서 본 연구는 집단의 한 시점에 대한 평균 비교가 아니라 기관절개술을 시행하지 않은 뇌졸중 환자와 기관절개술을 행한 뇌졸중 환자의 각 집단과 개인의 종단적 선형 성장률을 확인하고자 하였기 때문에 기존 연구와 차별화되는 결과를 도출하였다.

이에 따라 본 연구의 주요 결과는 각 집단의 목뼈 가동 범위 훈련에서 모두 개인 별로 효과 적인 양상을 나타내었 으나, 기관절개관을 삽입한 환자의 호흡과 기침능력을 유지 하거나 향상되는 폭이 부(-)적으로 더 어려운 것으로 관찰 되었다. 기관절개관 삽입 환자는 일반 뇌졸중 환자보다 호 흡이 더욱 어려운 특성에 따라 기초값이 더 낮을 수밖에 없 다. 특히 변화량에서 주로 호기 기능인 FEV1과 MPCF에서 성장률이 더디고 호흡기능의 향상을 지속하는 능력이 감소 하는 양상을 보였는데, 기관절개관을 삽입한 뇌졸중 환자는 기침의 강도가 낮고 기도흡인과 밀접한 연관성이 있기 때문 이라고 보여 진다. 이는 수의적 기침과 반사 기침 모두에서 기침의 강도와 기도흡인의 위험성이 상관관계가 있다는 결 론에서 근거한다[26]. 연하작용은 호흡기능과 해부학적인 측면에서 공유하고 있으며 기도절개관 환자들은 연하기능에 부정적 영향을 함께 포괄하고 있다[27]. 삼키는 동안 성문의 아래 압력은 필수적인데, 기관절개관은 후두를 묶어 후두가 상승하는 것을 방지하며, 기관을 개방시켜 성문의 아래 압 력을 형성하는 것이 불가능해지기 때문에 잠재적으로 후두 를 둔감하게 하며, 비 효과적인 기침 기전을 유발하게 된다 [28]. 더욱이 환자의 장기적인 기관절개관 삽입은 후두의 운 동 장애에 영향을 미친다고 보고되고 있다[29]. 따라서 기관 절개관을 삽입한 환자는 이러한 메커니즘으로 인해 종단적 으로 일반 뇌졸중 환자보다 호흡기능의 향상을 유지하는 것 이어렵고 성장률이 감소하는 것이라고 생각된다.

그러나 본 연구는 장기적인 종단 연구를 실시하지 않았 으며, 뇌졸중으로 인한 기관절개관을 삽입한 환자를 선별 하여 진행하였기 때문에 대상자 수가 많지 않아 일반화할 수 없는 한계점이 있었다. 그러므로 추후 연구에서는 보 다 많은 대상자를 선정하여 목뼈 가동 범위 훈련을 도입 하여 시행하여야 할 것이다. 또한 이전 연구와의 비교를 시행하였을 때, 다층성장모형을 도입한 연구가 미비하여 참조가 부족하였다. 따라서 관련 연구 뿐만 아니라 물리 치료분야의 다양한 연구에서 환자 개개인의 특성 비교와 궤적 관찰연구가 추가적으로 필요하다고 생각된다.
결론

본 연구의 결과에 의해 목뼈 가동 범위 훈련이 시간의 증가에 따라 일반 뇌졸중 환자와 기관절개관을 삽입한 뇌 졸중 환자의 호흡기능에 유용한 방법임을 입증하였다. 특 히 다층성장모형을 활용하여 전체 집단의 효과성 뿐만 아 니라 개인의 성장률을 파악하여 일반 뇌졸중 환자보다 기 관절개관을 삽입한 뇌졸중 환자의 호흡기능 향상 유지 궤 적이 더 낮음을 밝혀냈다. 본 연구는 궤적을 통해 각 개인 과 집단이 호흡기능에 미치는 변화량을 종단적 관찰로 가 시화할 수 있었다. 다시 말해, 집단 내의 각 개인이 어떠 한 기초 값을 가지고 효과를 보였는지, 성장률에 대하여 집단 혹은 개인 간에 차이가 있는지 여부를 관찰할 수 있 는 것이다. 이와 같이 다층성장모형 도입으로 본 연구는 기존 연구와 달리 종단적으로 목뼈 가동 범위 훈련을 적 용한 일반 뇌졸중 환자 및 기관절개관을 삽입한 뇌졸중 환자의 호흡과 기침유량의 효과의 유지가 증가 또는 감소 되는지 파악할 수 있어 의의가 크다고 볼 수 있다. 추후 물리치료 분야에서 본 연구를 기반으로 다층성장모형을 도입한 연구가 활발히 이루어지기를 기대하는 바이다.

\section{이해 충돌}

본 연구의 저자들은 연구, 저작권, 및 출판과 관련하여 잠재적인 이해충돌이 없음을 선언합니다.

\section{참고문헌}

1. Sarikaya H, Ferro J, Arnold M. Stroke prevention-medical and lifestyle measures. Eur Neurol. 2015;73(3-4):150-157.

2. Jung J-H, Kim N-S. The correlation between diaphragm thickness, diaphragmatic excursion, and pulmonary function in patients with chronic stroke. J Phys Ther Sci. 2017;29(12):2176-2179.

3. SANTOS RSad, DALL'ALBA SCF, Forgiarini SGI, Rossato D, Dias AS, Forgiarini Junior LA. Relationship between pulmonary function, functional independence, and trunk control in patients with stroke. Arq Neuropsiquiatr. 2019;77(6):387-392.

4. Masiero S, Pierobon R, Previato C, Gomiero E. Pneumonia in stroke patients with oropharyngeal dysphagia: a six-month follow-up study. Neurol Sci. 2008;29(3):139-145.

5. Bösel J, Schiller P, Hook Y, Andes M, Neumann 
J-O, Poli S, et al. Stroke-related early tracheostomy versus prolonged orotracheal intubation in neurocritical care trial (SETPOINT) a randomized pilot trial. Stroke. 2013;44(1):21-28.

6. Hsieh AH, Bishop MJ, Kubilis PS, Newell DW, Pierson DJ. Pneumonia following closed head injury. Am Rev Respir Dis. 1992;146(2):290-294.

7. Cooper JD. Tracheal Injuries Complicating Prolonged Intubation and Tracheostomy. Thorac Surg Clin. 2018;28(2):139-144.

8. Wilson RD. Mortality and cost of pneumonia after stroke for different risk groups. J Stroke Cerebrovasc Dis. 2012;21(1):61-67.

9. Turkstra TP, Craen RA, Pelz DM, Gelb AW. Cervical spine motion: a fluoroscopic comparison during intubation with lighted stylet, GlideScope, and Macintosh laryngoscope. Anesth Analg. 2005; 101(3):910-915.

10. Awadallah MF, Sobh E, Shendy MA, Al-Shenqiti AM, Al-Jeraisi TM, Eweda RS. Impaired pulmonary function in patients with chronic neck pain. $\mathrm{J}$ Med Sci. 2021;41(3):123.

11. Lee MH, Jang SH. The effects of the neck stabilization exercise on the muscle activity of trunk respiratory muscles and maximum voluntary ventilation of chronic stroke patients. J Back Musculoskelet Rehabil. 2019;32(6):863-868.

12. An HJ, Park SJ. Effects of Cervical Spine Mobilization on Respiratory Function and Cervical Angles of Stroke Patients: A Pilot Study. Healthcare. 2021;(4): 377

13. Raudenbush S, Bryk AS. A hierarchical model for studying school effects. Sociol Educ. 1986;59(1):1-17.

14. Tabachnick BG, Fidell LS, Ullman JB. Using multivariate statistics. Boston: Pearson; 2007.

15. Cleland JA, Mintken PE, Carpenter K, Fritz JM, Glynn P, Whitman J, et al. Examination of a clinical prediction rule to identify patients with neck pain likely to benefit from thoracic spine thrust manipulation and a general cervical range of motion exercise: multi-center randomized clinical trial. Phys Ther. 2010;90(9):1239-1250.

16. Lee JW, Cho HE, Kang S-W, Choi WA, Suh MR, Kim B. Correlation of Bone Mineral Density with Pulmonary Function in Advanced Duchenne Muscular Dystrophy. PM\&R. 2021;13(2):166-170.

17. Lee Y, Kim J, Jin Y. The efficacy of pulmonary re- habilitation using a mechanical in-exsufflator and feedback respiratory training for cervical cord injury patients. J Phys Ther Sci. 2012;24(1):89-92.

18. Raudenbush SW, Bryk AS. Hierarchical linear models: Applications and data analysis methods. 2nd ed. Thousand Oaks: sage; 2002.

19. Pekacka-Egli AM, Kazmierski R, Lutz D, Kulnik ST, Pekacka-Falkowska K, Maszczyk A, et al. Predictive Value of Cough Frequency in Addition to Aspiration Risk for Increased Risk of Pneumonia in Dysphagic Stroke Survivors: A Clinical Pilot Study. Brain Sci. 2021;11(7):847.

20. Gottdiener JS, Arnold AM, Aurigemma GP, Polak JF, Tracy RP, Kitzman DW, et al. Predictors of congestive heart failure in the elderly: the Cardiovascular Health Study. JACC CardioOncol. 2000;35(6):1628-1637.

21. Gregg I, Nunn A. Peak expiratory flow in normal subjects. Br Med. J1973;3(5874):282-284.

22. McCool FD. Global physiology and pathophysiology of cough: ACCP evidence-based clinical practice guidelines. Chest. 2006;129(1):48S-53S.

23. O'Connor HH, White AC. Tracheostomy decannulation. Respir Care 2010;55(8):1076-1081.

24. Jang SH, Bang HS. Effect of thoracic and cervical joint mobilization on pulmonary function in stroke patients. J Phys Ther Sci. 2016;28(1):257-260.

25. An HJ, Kim AY, Park SJ. Immediate Effects of Diaphragmatic Breathing with Cervical Spine Mobilization on the Pulmonary Function and Craniovertebral Angle in Patients with Chronic Stroke. Medicina. 2021;57(8):826.

26. Widdicombe J, Addington W, Fontana G, Stephens R. Voluntary and reflex cough and the expiration reflex; implications for aspiration after stroke. Pulm Pharmacol Ther. 2011;24(3):312-317.

27. Yang HE, Park YG, Kim SM. Correlation between respiratory function and dysphagia in stroke patients. J Korean Dysphagia Soc. 2014;4(1):23-27.

28. Pullens B, Streppel M. Swallowing problems in children with a tracheostomy. Semin Pediatr Surg. 2021;30(3):151053.

29. Pan DR, Jiang N. Outcomes of Intubation-induced Vocal Fold Motion Impairment. J Voice. 2020;34(2): 250-258. 